\title{
Elicitor induction of defence genes and reduction of bacterial canker in kiwifruit
}

\author{
K.V. Wurms ${ }^{1}$, E. Gould ${ }^{2}$, A. Ah Chee ${ }^{1}$, J. Taylor ${ }^{1}$, B. Curran ${ }^{3,4}$ and T. Reglinski ${ }^{1}$ \\ ${ }^{1}$ The New Zealand Institute for Plant \& Food Research Limited, Ruakura, Private Bag 3230, \\ Waikato Mail Centre, Hamilton 3240, New Zealand \\ ${ }^{2}$ Zespri International Limited, P.O. Box 4043, Mount Maunganui South, New Zealand \\ ${ }^{3}$ The New Zealand Institute for Plant \& Food Research Limited, Mount Albert Research \\ Centre, Private Bag 92169, Mount Albert, Auckland 1142, New Zealand \\ ${ }^{4}$ School of Biological Sciences, Faculty of Science, The University of Auckland, Private Bag \\ 92019, Auckland 1142, New Zealand \\ Corresponding author: kirstin.wurms@plantandfood.co.nz
}

\begin{abstract}
Pseudomonas syringae pv. actinidiae (Psa), which causes bacterial canker, is the most serious global pathogen of kiwifruit. Like most bacterial pathogens, control options are limited, but elicitors can reduce disease significantly, particularly those that induce the salicylic acid (SA) pathway. Acibenzolar-S-methyl (ASM), a SA analogue, is one of the most effective elicitors for Psa control. In this study, real-time PCR (qPCR) was used to measure the expression of 18 putative defence genes in Actinidia chinensis var. chinensis 'Hort16A' in response to Psa and ASM. Application of ASM led to up-regulation of RPM1 interacting protein 4 (RIN4), phenylalanine ammonia lyase (PAL), a hypersensitivity-induced response protein (HIRP), and $\beta$-1,3-glucosidase. Expression of PAL and HIRP was further enhanced when elicitor application and Psa-inoculation were combined. Elevated gene expression was correlated with decreased disease expression, and supports the hypothesis that elicitor-treated plants are primed to react more rapidly and/or strongly to pathogens.
\end{abstract}

Keywords Pseudomonas syringae pv. actinidiae, Psa, bacterial canker, kiwifruit, acibenzolarS-methyl, elicitor, defence genes, transcript expression, qPCR.

\section{INTRODUCTION}

Pseudomonas syringae pv. actinidiae (Psa) is a gram negative bacterium responsible for bacterial canker. It is considered to be one of the most devastating global pathogens of kiwifruit (Actinidia spp.) (Vanneste 2012; Michelotti et al. 2015), with Psa biovar 3 being responsible for the outbreak of bacterial canker in New Zealand.

Like most bacterial pathogens, effective control options for Psa are limited, with the cornerstones of control currently being copper pesticides and antibiotics (Reglinski et al, 2013). Disadvantages of using these products include phytotoxicity, heavy metal accumulation in the soil and development of resistance. The New Zealand kiwifruit industry is working towards inclusion of longer-term, more sustainable control measures that include breeding for resistance, the development of efficacious biologicals and the use of elicitors in integrated control programmes to temporarily induce host defences. 
Currently, Actigard ${ }^{\circledR}$ is the only elicitor registered for control of Psa on kiwifruit in New Zealand. It contains the salicylic acid analogue, acibenzolar-S-methyl (ASM), as its active ingredient. Successful use of elicitors requires a thorough understanding of the mechanisms and genes involved in the mode of action because efficacy under field conditions can vary with cultivar, timing and frequency of application, and crop phenology (Walters et al. 2011; Bruce 2014; Reglinski et al. 2014). In addition, an understanding of the mechanisms involved is needed to minimise the metabolic costs associated with elicitor use, such as reduced fruit production or quality (Walters \& Heil 2007; Cipollini \& Heil 2010). Despite the importance of ASM to Psa control in kiwifruit, there is little published information on its molecular mode of action, with only one study published to date examining the ASM-induced responses of five kiwifruit defence genes (Cellini et al. 2014). Consequently the current study was carried out to examine a wider range of putative markers of defence responses and also to determine whether pre-treatment with ASM enables some genes to respond more strongly to subsequent pathogen attack, a process known as priming.

\section{MATERIALS AND METHODS}

\section{Plant material, treatments and disease assessment}

All the tissue cultured Actinidia chinensis var. chinensis 'Hort16A' kiwifruit plants used in these experiments came from The New Zealand Institute for Plant \& Food Research Limited (PFR), Auckland as rooted plantlets in agar growth medium in plastic tubs. After transporting to PFR, Hamilton, plantlets were individually ex-flasked into 30-mm Rockwool ${ }^{\circledR}$ cubes (Rockwool BV, the Netherlands) and transferred to a containment glasshouse that was maintained at $15-24^{\circ} \mathrm{C}$, with a day length of approximately $14 \mathrm{~h}$. A flood and drain system was used once daily to water the plantlets with a hydroponic nutrient solution, $\mathrm{pH} 6.2$, containing calcium, iron, nitrates, sulphates, phosphates and trace elements (PGO Horticulture Limited,
New Zealand). Actively growing plantlets with 4-6 fully expanded true leaves were used for the experiment. Treatments comprised first spraying all leaves to run off with either ASM (1.7 mM) or water, followed by inoculation with Psa or water (mock inoculation) 14 days later. There were six plants per treatment (three replicates of two plants each), set up in a randomised block design. Up to $1.5 \mathrm{~g}$ of pooled leaf tissue (from 1-2 leaves/plant) was sampled 14 days after ASM/water pre-treatment (immediately prior to inoculation) and $48 \mathrm{~h}$ after Psa/mock inoculation for molecular studies.

After leaf removal, plants were maintained in the glasshouse for the purpose of disease assessment. The lengths of stem lesions ( $\mathrm{mm}$ ) were measured 4 weeks post-inoculation. Disease assessment data were analysed as a randomised block design by analysis of variance (ANOVA) $(\mathrm{P}<0.05)$, using Genstat $16^{\text {th }}$ edition.

\section{Inoculum preparation and inoculation technique}

Psa biovar 3 (strain \#10627, described by Vanneste et al. 2013) was plated onto King's B medium supplemented with cycloheximide $(0.018 \%)$ and boric acid $(0.136 \%)$, and incubated at $25^{\circ} \mathrm{C}$ for 24 h. Bacterial colonies were re-suspended in sterile water to a concentration of 109 colony forming units $(\mathrm{cfu}) / \mathrm{mL}$. Concentration was estimated by measurements of optical density with subsequent measurement by plating out and performing colony counts.

Plants were inoculated 14 days after pretreatment, by dipping toothpicks in either Psa $\left(10^{9} \mathrm{cfu} / \mathrm{mL}\right)$ or water (mock inoculation) and making a single puncture wound in soft tissue near the base of each plant stem.

\section{RNA extraction, genomic DNA removal and cDNA synthesis}

The sampled leaf tissue was snap frozen in liquid nitrogen and stored at $-80^{\circ} \mathrm{C}$ until RNA extraction. Total RNA was extracted from up to $1.5 \mathrm{~g}$ of frozen kiwifruit leaf discs using a modified version of the López-Gómez and Gómez-Lim method (1992), which is suitable for samples containing 
high levels of polyphenols and polysaccharides. Initially plant tissue was ground to fine powder by hand using liquid nitrogen in a mortar and pestle, followed by placement of the tissue into extraction buffer. Modifications to the López-Gómez and Gómez-Lim (1992) method included addition of polyvinylpolypyrrolidone $(0.5 \mathrm{~g})$ to the extraction buffer/ground tissue mix, and using a 1:1 mix of phenol and chloroform/isoamyl alcohol instead of phenol-chloroform (J. Bowen, PFR, unpublished data). RNA samples were quantified, and sample purity verified by using a Nanodrop ND-1000 spectrophotometer (Thermo Fisher) and RNA integrity was checked using an Agilent 2100 analyser (Agilent Technologies).

Total RNA was treated with deoxyribonuclease I (DNase) (Ambion, DNAse Turbo ${ }^{\mathrm{TM}}$, Thermo Fisher Scientific, Auckland, New Zealand), to remove any genomic DNA and was checked by PCR to confirm that there was no genomic contamination. Firststrand cDNA was synthesised, with random priming, in a $20 \mu \mathrm{L}$ reaction volume containing $1 \mu \mathrm{g}$ of DNase-treated RNA, using the SuperScript III first-strand synthesis system (Invitrogen Catalog No. 18085-051). Non-template controls included in each PCR plate were used to check the purity of the reagents.

\section{Quantitative polymerase chain reaction ( $\mathrm{PPCR}$ )} Quantitative PCR (qPCR) was used to investigate the transcriptional levels of 18 putative defence genes (Table 1) in the treated plants. Genes of interest (GoI) were selected based on published studies on Psa (Petriccione et al. 2013; Cellini et al. 2014; Petriccione et al. 2014) and other kiwifruit-pathogen interactions (Wurms 2005; Wurms et al. 2011b; Hill et al. 2015), as well as an unpublished next generation sequencing study of temporal gene expression in kiwifruit with and without Psa infection (A. Allan, PFR, New Zealand, unpublished data). qPCR was performed in triplicate on cDNA from three biological replicates in $10 \mu \mathrm{L}$ reactions containing $1 \mu \mathrm{L}$ of a 10 -fold dilution of the cDNA (for lowly expressed samples, runs were repeated with $2 \mu \mathrm{L}), 1 \mu \mathrm{M}$ of each of forward and reverse primers and $5 \mu \mathrm{L}$ of Light Cycler $^{\circledR}$ 480 SYBR Green 1 Master Mix (Roche Diagnostics GmbH, Mannheim, Germany, Product No. 04887352 001). The primers were designed using Primer3 software (Whitehead Institute, Cambridge, MA, USA) and were synthesised by Invitrogen (Auckland, New Zealand) (Table 1). Only primer pairs with efficiencies of $80 \%$ or greater were used in the experiment. qPCRs were carried out in a Corbett Rotor-Gene ${ }^{\mathrm{TM}} 6000$ system (Corbett Life Science, Concorde, NSW, Australia). The relative quantification thermal cycling conditions were: denaturation at $95^{\circ} \mathrm{C}$ for $10 \mathrm{~min}$, followed by 40 cycles of $15 \mathrm{~s}$ denaturation at $95^{\circ} \mathrm{C}, 15 \mathrm{~s}$ annealing at a different optimised temperature between 55 and $60^{\circ} \mathrm{C}$ for each primer set and $20 \mathrm{~s}$ extension at $72^{\circ} \mathrm{C}$. Inter-run variability was controlled by including a complete set of treatments on each plate, but a separate run for each biological replicate (i.e. three runs/primer set, which were then averaged). Melting curve analysis (60$95^{\circ} \mathrm{C}$ at $1^{\circ} \mathrm{C}$ increments with $5 \mathrm{~s}$ between each step) was performed after the final qPCR cycle to validate amplicon specificity. A preliminary experiment with six different reference genes (RG) was carried out to select the two RG that were most stably expressed under the conditions of the experiment (data not shown). These two RG, actin and 40s ribosomal protein (40s), were used for normalisation. A gene expression normalisation factor was calculated for the relative expression of each GoI using Normfinder and geNormv3.5, based on the geometric mean of actin and 40s. Expression of the treatments is expressed relative to the "water $14 \mathrm{~d}$ " control samples, which were assigned a value of 1 . 
Table 1 Accession numbers and primer sequences of reference genes (RG) and putative defence-related genes of interest (GoI) used in real-time PCR. All primers were designed in-house.

\begin{tabular}{lllll}
\hline Gene name & $\begin{array}{l}\text { Genebank } \\
\text { accession } \\
\text { number }\end{array}$ & $\begin{array}{l}\text { Forward } \\
\text { primer }\left(5^{\prime}-3^{\prime}\right)\end{array}$ & $\begin{array}{l}\text { Reverse primer } \\
\left(5^{\prime}-3^{\prime}\right)\end{array}$ & $\begin{array}{l}\text { Reason for selection and relevant } \\
\text { references }\end{array}$ \\
\hline RG: Actin & FG520231 & $\begin{array}{l}\text { TGCATGAGC- } \\
\text { GATCAA- } \\
\text { GTTTCAAG }\end{array}$ & $\begin{array}{l}\text { TGTCCCAT- } \\
\text { GTCTGGTT- } \\
\text { GATGACT }\end{array}$ & $\begin{array}{l}\text { Ubiquitous protein involved in } \\
\text { the formation of filaments of the } \\
\text { cytoskeleton and a common RG } \\
\text { for the Psa/kiwifruit interaction } \\
\text { (Henty-Ridilla et al. 2013; Petric- } \\
\end{array}$ \\
& & & $\begin{array}{l}\text { cione et al. 2015). Stable RG in this } \\
\text { experiment (exp). }\end{array}$ \\
& & & &
\end{tabular}

\begin{tabular}{llll}
\hline RG: 40 S Ribo- & FG498176 & GCAAAGG- & CCCCCTGTC- \\
somal Protein & & GATGTGAG- & TCAGAAGAA- \\
$(40 S)$ & GTGAT & CA
\end{tabular}

Involved in synthesis of protein

chains (Aitken and Lorsch 2012).

Stable RG in other kiwifruit/ pathogen interactions (Wurms et al. 2011a) and in this exp.

\begin{tabular}{llll}
\hline GoI: RPM1 & \multirow{2}{*}{ FG519750 } & CTTTGAGA- & TGTTCTTC- \\
interacting & & AAGCACG- & TGGTTCG- \\
protein 4 & & GAAGG & GTTC
\end{tabular}

Early stage defence - involved in (RIN4) AAGCACG- TGGTTCG- the guard cell response against bacterial pathogens (Liu et al. 2009). Significantly upregulated by salicylic acid (SA)-elicited, Psa-infected kiwifruit (Wurms et al. 2013).

\begin{tabular}{|c|c|c|c|c|}
\hline $\begin{array}{l}\text { GoI: Phenyla- } \\
\text { lanine ammo- } \\
\text { nia lyase, EC } \\
4.3 .1 .5 \text { (PAL) }\end{array}$ & $\begin{array}{l}\text { Not } \\
\text { released. } \\
\text { Closest } \\
\text { homo- } \\
\text { logue: } \\
\text { AAC18870 }\end{array}$ & $\begin{array}{l}\text { AAACGACA- } \\
\text { ACCCCTTG- } \\
\text { ATTG }\end{array}$ & $\begin{array}{l}\text { ACAAGCTC- } \\
\text { CGAAATTT- } \\
\text { GTGC }\end{array}$ & $\begin{array}{l}\text { Key regulatory enzyme of the phe- } \\
\text { nylpropanoid pathway (PPP), which } \\
\text { creates antimicrobial secondary me- } \\
\text { tabolites (Naoumkina et al. 2010). } \\
\text { Up-regulated by SA-elicitors which } \\
\text { decrease Psa infection (Cellini et al. } \\
2014) \text {. }\end{array}$ \\
\hline $\begin{array}{l}\text { GoI: Narin- } \\
\text { genin-chal- } \\
\text { cone synthase } \\
2 \text {, EC 2.3.1.74 } \\
\text { (CHS) }\end{array}$ & & $\begin{array}{l}\text { GTCAAGCGC- } \\
\text { CTCATGATG- } \\
\text { TA }\end{array}$ & $\begin{array}{l}\text { ATCACTGGG- } \\
\text { TCCACGAAA- } \\
\text { AG }\end{array}$ & $\begin{array}{l}\text { Key regulatory enzyme of the PPP, } \\
\text { which creates antimicrobial second- } \\
\text { ary metabolites (Naoumkina et al. } \\
2010) \text {. }\end{array}$ \\
\hline $\begin{array}{l}\text { GoI: Glucan } \\
\text { endo-1,3-be- } \\
\text { ta-glucosidase } \\
\text { EC 3.2.1.39 } \\
\text { ( } \beta \text {-1,3- } \\
\text { glucosidase) }\end{array}$ & & $\begin{array}{l}\text { TTGGTTCA- } \\
\text { ACATGTCAA- } \\
\text { AGGAG }\end{array}$ & $\begin{array}{l}\text { TAGGCTGCT- } \\
\text { TGTTGGGAA- } \\
\text { AG }\end{array}$ & $\begin{array}{l}\text { Thought to convert preformed inert } \\
\text { phytoanticipins (synthesized via } \\
\text { the PPP) into their corresponding } \\
\text { toxic aglycones (Morant et al. 2008). } \\
\text { Involved in other kiwifruit pest/ } \\
\text { pathogen interactions (Wurms et al. } \\
\text { 2011a; Hill et al. 2015). }\end{array}$ \\
\hline
\end{tabular}


Table 1 Continued. Accession numbers and primer sequences of reference genes (RG) and putative defence-related genes of interest (GoI) used in real-time PCR. All primers were designed in-house.

\begin{tabular}{|c|c|c|c|c|}
\hline Gene name & $\begin{array}{l}\text { Genebank } \\
\text { accession } \\
\text { number }\end{array}$ & $\begin{array}{l}\text { Forward } \\
\text { primer }\left(5^{\prime}-3^{\prime}\right)\end{array}$ & $\begin{array}{l}\text { Reverse primer } \\
\left(5^{\prime}-3^{\prime}\right)\end{array}$ & $\begin{array}{l}\text { Reason for selection and relevant } \\
\text { references }\end{array}$ \\
\hline $\begin{array}{l}\text { GoI: PIRL5 } \\
\text { leucine rich } \\
\text { repeat fam- } \\
\text { ily protein } \\
\text { (PIRL5) }\end{array}$ & FG474061 & $\begin{array}{l}\text { CCAGAG- } \\
\text { CAAAGAGCA- } \\
\text { GAAGAAGG }\end{array}$ & $\begin{array}{l}\text { GAATGCAT- } \\
\text { CTCGAG- } \\
\text { GCTCTCTG }\end{array}$ & $\begin{array}{l}\text { Involved in signal transduction } \\
\text { (Forsthoefel et al. 2005). }\end{array}$ \\
\hline $\begin{array}{l}\text { GoI: Leucine } \\
\text { rich repeat } \\
\text { protein (LRR } \\
\text { protein) }\end{array}$ & FG484930 & $\begin{array}{l}\text { ACTGCAG- } \\
\text { CATGCTTG- } \\
\text { GACTC }\end{array}$ & $\begin{array}{l}\text { CTTTCAGA- } \\
\text { TTCCGTAGC- } \\
\text { CCCG }\end{array}$ & $\begin{array}{l}\text { Putative resistance }(\mathrm{R}) \text { gene } \\
\text { (Belkhadir et al. 2004). }\end{array}$ \\
\hline $\begin{array}{l}\text { GoI: Mito- } \\
\text { gen-activated } \\
\text { protein ki- } \\
\text { nase kinase } 2 \\
\text { (MAPKKK) }\end{array}$ & FG474586 & $\begin{array}{l}\text { TATATCCGC- } \\
\text { GATCACT- } \\
\text { GTGG }\end{array}$ & $\begin{array}{l}\text { ACAACCCCA- } \\
\text { GATGCATT- } \\
\text { GAC }\end{array}$ & $\begin{array}{l}\text { Central point in defence in plant } \\
\text { defence signalling cascades (del } \\
\text { Pozo et al. 2004; He et al. 2006; } \\
\text { Wang et al. 2014). Up-regulated } \\
\text { in 'Hayward' kiwifruit } 6 \text { days after } \\
\text { treatment with methyl jasmonate } \\
\text { (MeJa) elicitor, which induces } \\
\text { resistance to botrytis and insects } \\
\text { (K. Wurms, PFR, New Zealand, } \\
\text { unpublished data). }\end{array}$ \\
\hline $\begin{array}{l}\text { GoI: Hy- } \\
\text { persenstive } \\
\text { induced } \\
\text { response pro- } \\
\text { tein (HIRP) }\end{array}$ & FG459556 & $\begin{array}{l}\text { GCTGCTA- } \\
\text { GAATGAG- } \\
\text { GGTTGC }\end{array}$ & $\begin{array}{l}\text { TCCCTCAGT- } \\
\text { CCGTCAAC- } \\
\text { AAT }\end{array}$ & $\begin{array}{l}\text { Involved in hypersensitive response } \\
\text { (HR) in Arabidopsis to bacterial } \\
\text { pathogens (Qi et al. 2011). }\end{array}$ \\
\hline $\begin{array}{l}\text { GoI: Pattern } \\
\text { triggered im- } \\
\text { munity recep- } \\
\text { tor like kinase } \\
\text { (RLK) }\end{array}$ & FG485280 & $\begin{array}{l}\text { TGAGCAA- } \\
\text { GGTGTGC- } \\
\text { ATGAAT }\end{array}$ & $\begin{array}{l}\text { CTCCCGAA- } \\
\text { GAGTTCCAT- } \\
\text { GAG }\end{array}$ & $\begin{array}{l}\text { A senescence-induced receptor } \\
\text { kinase (serine/threonine kinase) } \\
\text { that triggers defence responses upon } \\
\text { recognition of the elicitor flagellin } \\
\text { (Robatzek and Somssich 2002) }\end{array}$ \\
\hline $\begin{array}{l}\text { GoI: } \\
\text { Chitinase }\end{array}$ & FG512537 & $\begin{array}{l}\text { GGTTGCT- } \\
\text { GCTTTTC- } \\
\text { TTGCTC }\end{array}$ & $\begin{array}{l}\text { CACAAGGC- } \\
\text { CACTGTT- } \\
\text { GATTG }\end{array}$ & $\begin{array}{l}\text { Endochitinase (PR3 protein). } \\
\text { Highly up-regulated protein in a } \\
\text { kiwifruit-scale insect interaction } \\
\text { (Hill et al. 2015). }\end{array}$ \\
\hline $\begin{array}{l}\text { GoI: } \\
\text { Thaumatin- } \\
\text { like protein } \\
\text { (TLP) }\end{array}$ & FG417283 & $\begin{array}{l}\text { TGTCAATAT- } \\
\text { CACGGGCA- } \\
\text { ATG }\end{array}$ & $\begin{array}{l}\text { ATCGGACAC- } \\
\text { CTCTTCTTGA }\end{array}$ & $\begin{array}{l}\text { PR5 protein family. Highly up- } \\
\text { regulated protein in a kiwifruit- } \\
\text { scale insect interaction (Hill et al. } \\
\text { 2015). }\end{array}$ \\
\hline
\end{tabular}


Table 1 Continued. Accession numbers and primer sequences of reference genes (RG) and putative defence-related genes of interest (GoI) used in real-time PCR. All primers were designed in-house.

\begin{tabular}{|c|c|c|c|c|}
\hline Gene name & $\begin{array}{l}\text { Genebank } \\
\text { accession } \\
\text { number }\end{array}$ & $\begin{array}{l}\text { Forward } \\
\text { primer }\left(5^{\prime}-3^{\prime}\right)\end{array}$ & $\begin{array}{l}\text { Reverse primer } \\
\left(5^{\prime}-3^{\prime}\right)\end{array}$ & $\begin{array}{l}\text { Reason for selection and relevant } \\
\text { references }\end{array}$ \\
\hline $\begin{array}{l}\text { GoI: } \\
\text { Phytoalexin } \\
\text { deficient } 4 \\
\text { triacylglycerol } \\
\text { lipase (PAD4) }\end{array}$ & FG479414 & $\begin{array}{l}\text { ATGCTCGT- } \\
\text { GACAGGAA- } \\
\text { ACGC }\end{array}$ & $\begin{array}{l}\text { GCAATGC- } \\
\text { CAATGTA- } \\
\text { ACACCTGC }\end{array}$ & $\begin{array}{l}\text { The Arabidopsis PAD } 4 \text { gene was } \\
\text { previously shown to be required for } \\
\text { synthesis of camalexin in response } \\
\text { to infection by the virulent bacterial } \\
\text { pathogen Pseudomonas syringae pv. } \\
\text { maculicola. PAD4 mutants } \\
\text { exhibit defects in defence responses, } \\
\text { including camalexin synthesis and } \\
\text { pathogenesis-related PR-1 gene } \\
\text { expression (Glazebrook et al. 1997) }\end{array}$ \\
\hline $\begin{array}{l}\text { GoI: Coiled } \\
\text { coil- nucleo- } \\
\text { tide binding } \\
\text { site- leucine } \\
\text { rich repeat } \\
\text { resistance (R) } \\
\text { protein (CC- } \\
\text { NBS-LRR) }\end{array}$ & FG407814 & $\begin{array}{l}\text { AGACTTTGA- } \\
\text { AGATGCCCC- } \\
\text { CTTGC }\end{array}$ & $\begin{array}{l}\text { TGTAGCCT- } \\
\text { GCCAATT- } \\
\text { GACTTTGG }\end{array}$ & $\begin{array}{l}\text { Putative R gene (Belkhadir et al. } \\
\text { 2004). }\end{array}$ \\
\hline $\begin{array}{l}\text { GoI: Toll and } \\
\text { interleukin-1 } \\
\text { region- nucle- } \\
\text { otide binding } \\
\text { site- leucine } \\
\text { rich repeat R } \\
\text { protein (TIR- } \\
\text { NBS-LRR) }\end{array}$ & FG525643 & $\begin{array}{l}\text { GTCTGGC- } \\
\text { AGGGTTG- } \\
\text { GTCTTG }\end{array}$ & $\begin{array}{l}\text { GTAACACT- } \\
\text { GAGGACCGT- } \\
\text { GCG }\end{array}$ & $\begin{array}{l}\text { R gene active in tobacco mosaic } \\
\text { virus resistance in tobacco plants } \\
\text { (Dinesh-Kumar et al. 2000). } \\
\text { Blasting FG52564 against a PFR } \\
\text { kiwifruit scaffold, it was possible to } \\
\text { construct a putative protein with all } \\
3 \text { domains identified. }\end{array}$ \\
\hline GoI: FLS2 & $\begin{array}{l}\text { Not re- } \\
\text { leased. } \\
\text { Closest } \\
\text { homologue: } \\
\text { XM006478- } \\
712.2\end{array}$ & $\begin{array}{l}\text { GCGAGTG- } \\
\text { TTGTACCT- } \\
\text { GCAAA }\end{array}$ & $\begin{array}{l}\text { TCACAT- } \\
\text { GAAATCC- } \\
\text { CAGTCCA }\end{array}$ & $\begin{array}{l}\text { A receptor-like kinase involved in } \\
\text { perception of the bacterial elicitor } \\
\text { flagellin (Qi et al. 2011). }\end{array}$ \\
\hline $\begin{array}{l}\text { GoI: } \\
\text { RING-H2 } \\
\text { finger } \\
\text { protein } \\
\text { ATL2M } \\
\text { (RING-H2 } \\
\text { finger) }\end{array}$ & FG485058 & $\begin{array}{l}\text { CGGGGTCA- } \\
\text { GTGATTGC- } \\
\text { TCTA }\end{array}$ & $\begin{array}{l}\text { GACACGAT- } \\
\text { GCGTTCAG- } \\
\text { CTTC }\end{array}$ & $\begin{array}{l}\text { RING finger proteins are involved in } \\
\text { Arabidopsis resistance against } \\
\text { Pseudomonas syringae (Kawasaki et } \\
\text { al. 2005). Co-presents with ethylene } \\
\text { insensitive protein and was up-reg- } \\
\text { ulated in Hayward fruit } 3 \text { days after } \\
\text { treatment with MeJa (K. Wurms, PFR, } \\
\text { New Zealand, unpublished data). }\end{array}$ \\
\hline
\end{tabular}


Table 1 Continued. Accession numbers and primer sequences of reference genes (RG) and putative defence-related genes of interest (GoI) used in real-time PCR. All primers were designed in-house.

\begin{tabular}{|c|c|c|c|c|}
\hline Gene name & $\begin{array}{l}\text { Genebank } \\
\text { accession } \\
\text { number }\end{array}$ & $\begin{array}{l}\text { Forward } \\
\text { primer }\left(5^{\prime}-3^{\prime}\right)\end{array}$ & $\begin{array}{l}\text { Reverse primer } \\
\left(5^{\prime}-3^{\prime}\right)\end{array}$ & $\begin{array}{l}\text { Reason for selection and relevant } \\
\text { references }\end{array}$ \\
\hline $\begin{array}{l}\text { GoI: Ethyl- } \\
\text { ene-insensi- } \\
\text { tive protein } \\
2 \text {, cytokinin } \\
\text { resistant pro- } \\
\text { tein AtCKR1 } \\
(\text { EIN2) }\end{array}$ & FG469211 & $\begin{array}{l}\text { TTGTTTGAT- } \\
\text { GCTTTGGC- } \\
\text { TTG }\end{array}$ & $\begin{array}{l}\text { TCTCCGC- } \\
\text { AGATGAA- } \\
\text { TCAGG }\end{array}$ & $\begin{array}{l}\text { Ethylene/cytokinin resistant and } \\
\text { co-presented with ring finger-H2 } \\
\text { protein Up-regulated in Hayward } \\
\text { fruit } 3 \text { days after treatment with } \\
\text { MeJa (Wurms, PFR, New Zealand, } \\
\text { unpublished data). }\end{array}$ \\
\hline $\begin{array}{l}\text { GoI: } \\
\text { Acyl lipidase }\end{array}$ & FG475093 & $\begin{array}{l}\text { CAGGATT- } \\
\text { TAGTAGCA- } \\
\text { ATGATGGAC }\end{array}$ & $\begin{array}{l}\text { AAGGGA- } \\
\text { TCCTCTC- } \\
\text { GTAATCCA }\end{array}$ & $\begin{array}{l}\text { Up-regulated protein in a kiwifruit- } \\
\text { scale insect interaction (Hill et al. } \\
\text { 2015) Modified expression of acyl } \\
\text { lipids affects host resistance to path- } \\
\text { ogens (La Camera et al. 2005). }\end{array}$ \\
\hline
\end{tabular}

\section{RESULTS}

\section{Disease assessment}

Only Psa inoculation resulted in spread of moist lesions along the stem and tissue softening within the lesion, whilst the highly localised, 1-3 mm lesions associated with the mock inoculation treatments consisted of a dry wound response associated with the stab inoculation method (Figure 1).

Pre-treatment with ASM, as opposed to water, significantly reduced the severity of Psa infection $(\mathrm{P}<0.001)$, achieving a $50 \%$ reduction in stem lesion length (Figure 2).

\section{Gene expression}

HIRP, RIN4, and most especially $\beta-1,3-$ glucosidase, were up-regulated in response to ASM alone, and there was a synergistic increase in PAL, and HIRP expression when ASM-elicited plants were inoculated with Psa (Figure 3). None of these genes responded to the pathogen alone. In contrast, expression of PAD4, FLS2, CC-NBSLRR, RING-H2 finger and EIN2 transcripts only increased strongly in the presence of the pathogen alone, and this reaction was masked if the plants were pre-treated with ASM (Figure 4). The reaction of FLS2 to the pathogen was the strongest (Figure 4).
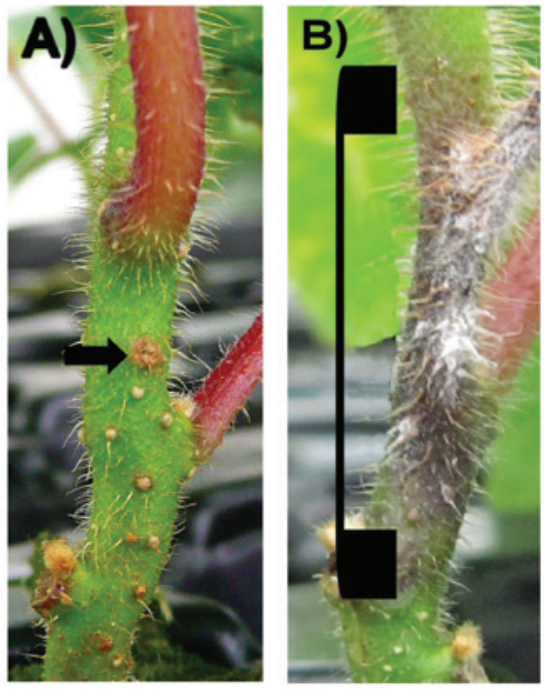

Figure 1 Close-ups of inoculation points on stems of glasshouse grown, tissue cultured Actinidia chinensis var. deliciosa 'Hayward' plantlets 4 weeks post inoculation with (A) water (mock inoculation); or a $10^{9} \mathrm{cfu} / \mathrm{mL}$ suspension of (B) Pseudomonas syringae pv. actinidiae (Psa). The arrow in (A) indicates a localised light brown dry wound site at the point of inoculation, whilst the bracketed dark brown region on (B) shows the extent of fungal lesion spread along the otherwise healthy green stem. 


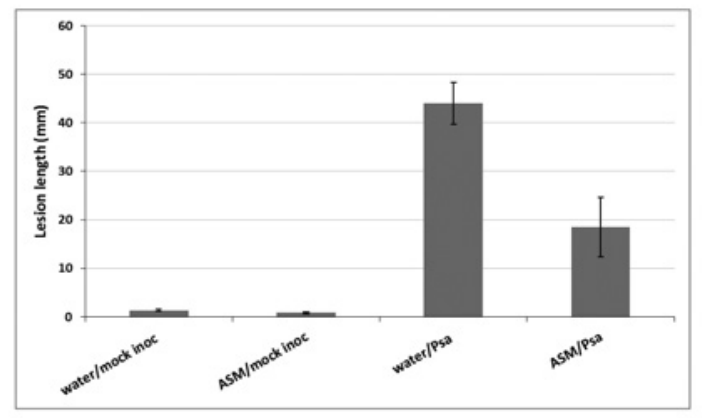

Figure 2 Pseudomonas syringae pv. actinidiae (Psa) disease severity on Actinidia chinensis var chinensis 'Hort16A' kiwifruit plantlets, as measured by stem lesion length, 4 weeks after stab inoculation with Psa $\left(10^{9} \mathrm{cfu} / \mathrm{mL}\right)$ or water (mock inoc). Plants were treated with water or Acibenzolar-S-methyl (ASM) 14 days before inoculation. Error bars indicate standard error of the mean (SEM). There were six replicate plants per treatment and a randomised block design was used.
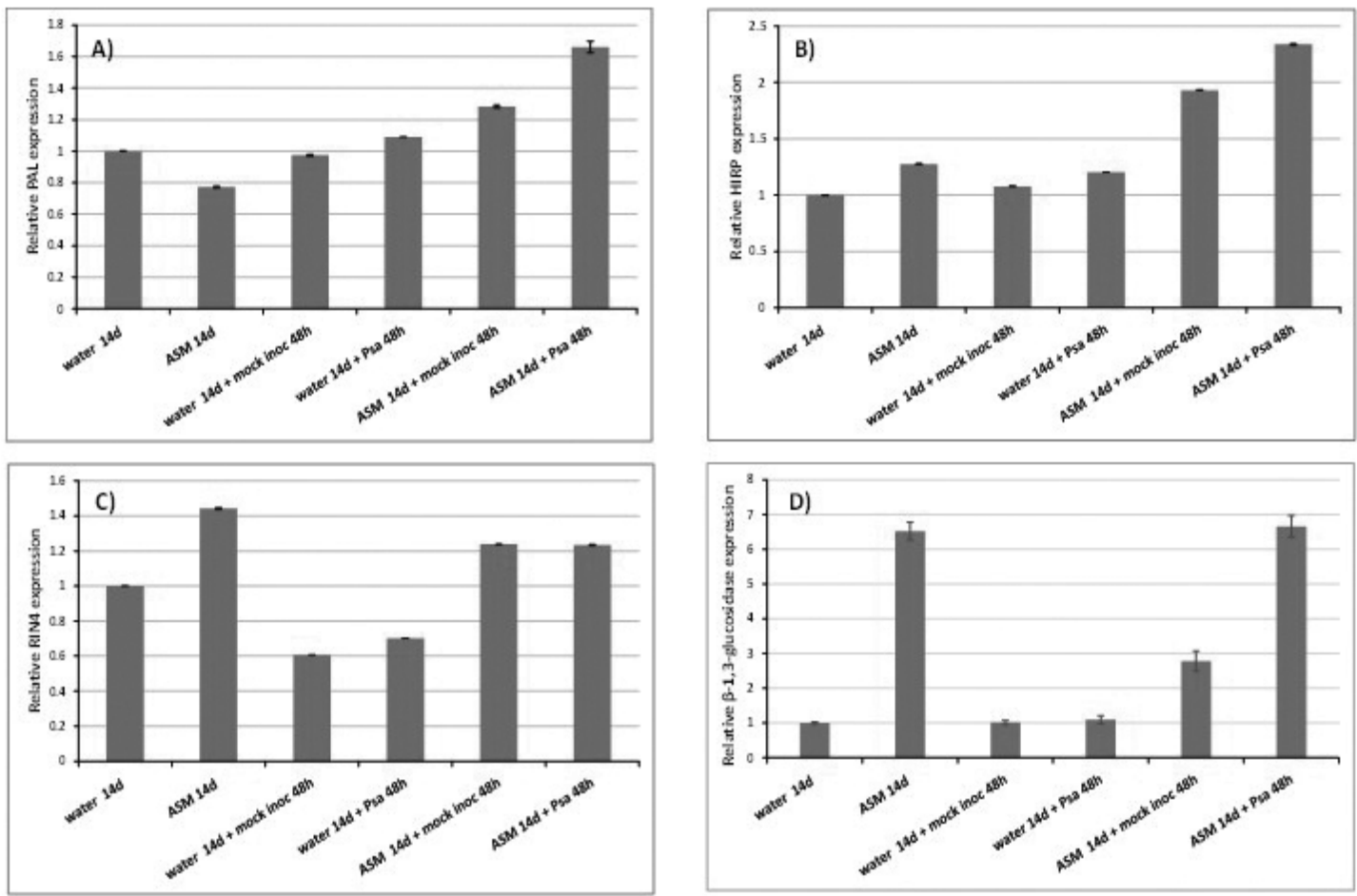

Figure 3 Relative abundance of five kiwifruit putative defence transcripts as measured by quantitative PCR (qPCR) 14 days after treatment with water or Acibenzolar-S-methyl (ASM) elicitor, and $48 \mathrm{~h}$ after stab inoculation with water (mock inoc) or Pseudomonas syringae pv. actinidiae (Psa) $\left(10^{9} \mathrm{cfu} / \mathrm{mL}\right)$. A) relative phenylalanine ammonia lyase (PAL) expression; B) relative hypersensitivityinduced response protein (HIRP) expression; C) relative RIN4 expression; and D) relative $\beta-1,3$ glucosidase expression. Error bars indicate standard error of the mean (SEM), where $n=3$ replicates (consisting of pooled leaf tissue). 

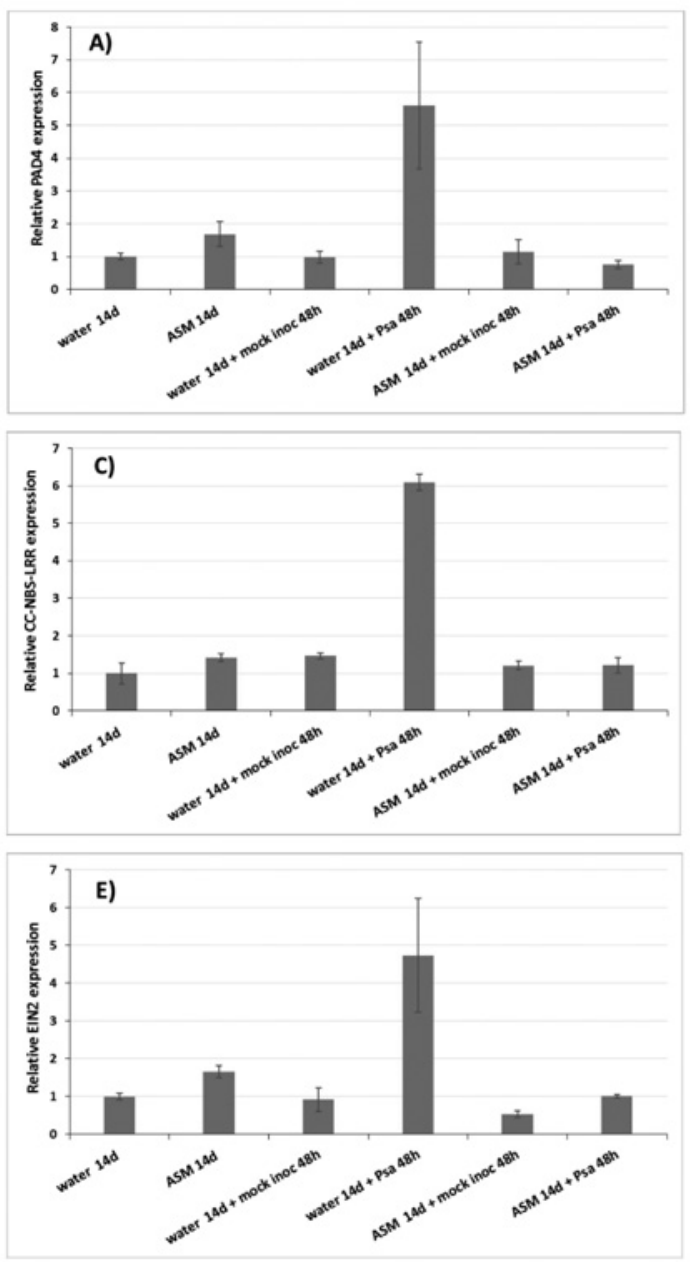

Of the 18 genes tested, 9 genes (CHS, PIRL5, LRR protein, MAPKKK, RLK, Chitinase, TLP, TIR-NBS-LRR and Acyl lipidase) did not show any marked increase or decrease in expression with any of the treatments, and did not exceed the commonly used cut-off of \pm 2 -fold changes in differential expression (Mosqueira et al. 2012; Meimoun et al. 2014; Damian-Zamacona et al. 2016), so are not presented here.

\section{DISCUSSION}

The salicylic acid analogue ASM reduced severity of bacterial canker in kiwifruit by $50 \%$. This result correlated with elevated host defence gene expression of HIRP, RIN4 and $\beta-1,3$ -
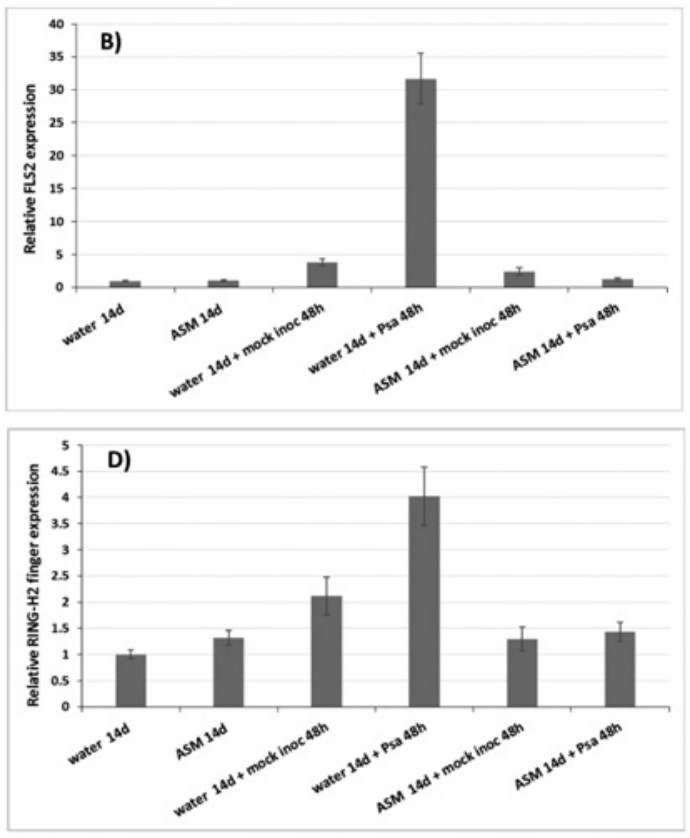

Figure 4 Relative abundance of five kiwifruit putative defence transcripts as measured by qPCR 14 days after treatment with water or AcibenzolarS-methyl (ASM) elicitor, and $48 \mathrm{~h}$ after stab inoculation with water (mock inoc) or Pseudomonas syringae pv. actinidiae (Psa) $\left(10^{9} \mathrm{cfu} / \mathrm{mL}\right)$. A) relative phytoalexin deficient 4 triacylglycerol lipase (PAD4) expression; B) relative FLS2 expression; C) relative coiled coil- nucleotide binding site- leucine rich repeat resistance $(\mathrm{R})$ protein (CC-NBS-LRR) expression; D) relative RING-H2 finger protein ATL2M (RING-H2 finger) expression; and E) relative ethylene-insensitive protein 2 , cytokinin resistant protein AtCKR1 (EIN2) expression. The relative concentration of CC-NBS-LRR cDNA was double that for all the other genes because changes in expression were very small and so the qPCR runs were repeated using a higher concentration of cDNA. Error bars indicate standard error of the mean (SEM), where $\mathrm{n}=3$.

glucosidase in response to ASM alone, and a synergistic increase in PAL and HIRP expression when ASM-elicited plants were inoculated with Psa. These findings support the hypothesis that elicitor-treated plants are primed to react more 
rapidly and/or strongly to pathogens.

Acibenzolar-S-methyl appears to be inducing host defence proteins including key genes involved in effector triggered immunity (ETI) such as HIRP and RIN4, and enzymes associated with the phenylpropanoid pathway, including PAL, and $\beta$-1,3-glucanase. Effector triggered immunity is characterised by pathogen effectors interacting with host resistance $(\mathrm{R})$ genes and is highly racespecific (Thomma et al. 2011). The HIRP and RIN4 genes are thought to play key roles in primary defence by interacting with host $\mathrm{R}$ genes. The Psa effectors of pathovar 3, the pathovar used in this experiment, are well characterised (Rikkerink et al. 2015) and would likely interact with genes like RIN4 and HIRP via their association with host $\mathrm{R}$ genes. PAL is a key regulatory enzyme in the phenylpropanoid pathway (Naoumkina et al. 2010) that produces antimicrobial compounds. This experiment demonstrated a synergistic increase in PAL expression (relative to plants treated with ASM or Psa alone), along with a significant reduction in disease severity, in inoculated kiwifruit plants that had been primed by treatment with ASM. Although Cellini et al. (2014) used a different primer pair for PAL is also found that ASM treatment significantly reduced Psa infection and that induction of PAL by ASM was both faster and greater in the more resistant Actinidia chinensis var. deliciosa 'Hayward' cultivar than in the more susceptible 'Hort16A' cultivar. As well as being responsible for the production of many antimicrobial secondary metabolites, PAL is also involved in the synthesis of SA (Naoumkina et al. 2010; Dempsey et al. 2011). Glucosidases, such as $\beta$-1,3-glucanase, enable the plant to respond immediately to pathogen invasion by converting preformed inert storage forms of products from the phenylpropanoid pathway into their corresponding toxic counterparts by sugar hydrolysis (Osbourn 1996; Zagrobelny et al. 2004; Morant et al. 2008). $\beta-1,3$-Glucosidases can also hydrolyse conjugated plant hormones, e.g. endogenous SA conjugates, thereby altering their bioactivity (Minic 2008), and enzyme hydrolysis can also produce elicitor compounds. In addition, glucosidases are considered to be pathogenesis- related (PR) proteins, being closely related to the PR2 family of enzymes (glucanases), which are often used as markers of the SA-pathway (Thatcher et al. 2005; Minic 2008). Given that ASM induced $\beta$-1,3-glucanase more strongly than any other marker tested, this suggests that this enzyme may play an important role in resistance induced by ASM, although in this case there was no priming effect of the elicitor. However, further work involving temporal studies of transcript expression, proteomic studies and possibly gene silencing experiments are required to confirm this hypothesis.

Psa treatment alone strongly induced FLS2, CC-NBS-LRR, PAD4, RING-H2 finger and EIN2 transcripts, but this reaction was masked if the plants were pre-treated with ASM. We might expect these transcripts to respond strongly to Psa, because these genes are involved in recognition of the pathogen and the plant defence response to it. The FLS2 transcript is an immune receptor at the plant surface that recognises the pathogen-associated molecular pattern (PAMP) of flg22, a 22-amino acid peptide of bacterial flagellin, and consequently initiates patterntriggered immunity (PTI) (Qi et al. 2011). The strong response FLS2 to Psa in this experiment suggests that it is successfully recognising flg22 in Psa flagellin. Based on conserved patterns in its nucleotide sequence, CC-NBS-LRR is a putative kiwifruit $\mathrm{R}$ gene that has been seen to respond to scale-insect challenge (Hill et al. 2015). Host R genes that are involved in ETI and the expression of CC-NBS-LRR are likely to be responding to Psa effectors in this experiment. However, $\mathrm{R}$ gene expression is often quite low (E. Rikkerink, pers. comm., PFR, New Zealand), which explains why the standard amount of cDNA in our qPCR reactions had to be doubled. The PAD4 and RING-H2 finger transcripts and the coexpressed EIN2 transcripts have been shown to be involved in Arabidopsis resistance against Pseudomonas syringae (Glazebrook et al. 1997; Kawasaki et al. 2005). Whilst up-regulation of these transcripts in response to Psa inoculation makes biological sense, the low level of induction of these genes when Psa-inoculated kiwifruit 
plants were pre-treated with ASM is harder to explain. One possible explanation might be that there is a lowered generalised stress response due to successful priming as some of these genes, such as EIN2, respond to a broad range of abiotic and biotic triggers (Alonso et al. 1999). Since elicitation of defences is energy demanding on the host, another explanation might be that pretreatment with ASM causes the plant to divert its resources away from ineffective resistance mechanisms. Since greater disease resistance was obtained with ASM treatment, this in turn suggests that these genes were not involved in that resistance since their expression was suppressed. Finally, in the case of PAD4 expression, a different explanation may apply. The application of ASM mimics SA accumulation to some extent, which in turn negates the requirement for PAD4 expression, as this generally occurs upstream of SA accumulation (Cui et al. 2017).

Two primer pairs in this study, PAL and HIRP have been used to successfully demonstrate the priming effect of ASM, and these two genes, in addition to RIN4 and $\beta$-1,3-glucosidase, appear to serve as useful markers of ASM-induced resistance to Psa in kiwifruit. This research has also identified a further five Psa-induced genes, FLS2, CC-NBS-LRR, PAD4, RING-H2 finger and EIN2, which may be useful markers for studying the kiwifruit-Psa interaction. Further research is required, and future qPCR studies will examine cultivar-specific responses to ASM and other elicitors and the timing of expression of putative defence markers. The information will be used to help optimise elicitor application strategies for different cultivars thus contributing to longerterm, more sustainable Psa control measures for the New Zealand kiwifruit industry.

\section{ACKNOWLEDGEMENTS}

Special thanks to Deirdre Cornish and Janet Yu for preparing the Psa inoculum, to Mike Spiers for statistical analysis, and to Drs Andrew Allan, Erik Rikkerink and Joanna Bowen for editorial comments. This work was funded by the New Zealand Ministry of Business, Innovation and Employment.

\section{REFERENCES}

Aitken CE, Lorsch JR 2012. A mechanistic overview of translation initiation in eukaryotes. Nature Structural \& Molecular Biology 19: 568-576.

Alonso JM, Hirayama T, Roman G, Nourizadeh S, Ecker JR 1999. EIN2, a bifunctional transducer of ethylene and stress responses in Arabidopsis. Science 284: 2148-2152.

Belkhadir Y, Subramaniam R, Dangl JL 2004. Plant disease resistance protein signaling: NBS-LRR proteins and their partners. Current Opinion in Plant Biology 7: 391-399.

Bruce TJA 2014. Variation in plant responsiveness to defense elicitors caused by genotype and environment. Frontiers in Plant Science 5: 4. doi: 10.3389/fpls.2014.00349

Cellini A, Fiorentini L, Buriani G, Yu J, Donati I, Cornish DA, Novak B, Costa G, Vanneste JL, Spinelli F 2014. Elicitors of the salicylic acid pathway reduce incidence of bacterial canker of kiwifruit caused by Pseudomonas syringae pv. actinidiae. Annals of Applied Biology 165: 441-453.

Cipollini D, Heil M 2010. Costs and benefits of induced resistance to herbivores and pathogens in plants. $\mathrm{CAB}$ Reviews: Perspectives in Agriculture, Veterinary Science, Nutrition and Natural Resources 5: 1-25.

Cui HT, Gobbato E, Kracher B, Qiu JD, Bautor J, Parker JE 2017. A core function of EDS1 with PAD4 is to protect the salicylic acid defense sector in Arabidopsis immunity. New Phytologist 213: 1802-1817.

Damian-Zamacona S, Toledo-Ibelles P, IbarraAbundis MZ, Uribe-Figueroa L, HernandezLemus E, Macedo-Alcibia KP, Delgado-Coello B, Mas-Oliva J, Reyes-Grajeda JP 2016. Early transcriptomic response to LDL and oxLDL in human vascular smooth muscle cells. PLoS ONE 11. doi: 10.1371/journal.pone.0163924

Del Pozo O, Pedley KF, Martin GB 2004. MAPKKK alpha is a positive regulator of cell death associated with both plant immunity and disease. EMBO Journal 23: 3072-3082.

Dempsey DMA, Vlot AC, Wildermuth MC, Klessig, DF 2011. Salicylic acid biosynthesis 
and metabolism. The Arabidopsis book / American Society of Plant Biologists 9: e0156-e0156. doi: 10.1199/tab.0156

Dinesh-Kumar SP, Tham WH, Baker, BJ 2000. Structure-function analysis of the tobacco mosaic virus resistance gene N. Proceedings of the National Academy of Sciences of the United States of America 97: 14789-14794.

Forsthoefel NR, Cutler K, Port MD, Yamamoto T, Vernon DM 2005. PIRLs: A novel class of plant intracellular leucine-rich repeat proteins. Plant Cell Physiology 46: 913-922.

Glazebrook J, Zook M, Mert F, Kagan I, Rogers EE, Crute IR, Holub EB, Hammerschmidt R, Ausubel FM 1997. Phytoalexin-deficient mutants of Arabidopsis reveal that PAD4 encodes a regulatory factor and that four PAD genes contribute to downy mildew resistance. Genetics 146: 381-392.

He P, Shan L, Lin NC, Martin GB, Kemmerling B, Nurnberger T, Sheen J 2006. Specific bacterial suppressors of MAMP signaling upstream of MAPKKK in Arabidopsis innate immunity. Cell 125: 563-575.

Henty-Ridilla JL, Li JJ, Blanchoin L, Staiger CJ 2013. Actin dynamics in the cortical array of plant cells. Current Opinion in Plant Biology 16: 678-687.

Hill MG, Wurms KV, Davy MW, Gould E, Allan A, Mauchline NA, Luo Z, Ah Chee A, Stannard K, Storey RD, Rikkerink EH 2015. Transcriptome analysis of kiwifruit (Actinidia chinensis) bark in response to armoured scale insect (Hemiberlesia lataniae) feeding. PLoS ONE 10. doi: 10.1371/journal. pone.0141664

Kawasaki T, Nam J, Boyes DC, Holt BF, Hubert DA, Wiig A, Dangl JL 2005. A duplicated pair of Arabidopsis RING-finger E3 ligases contribute to the RPM1-and RPS2-mediated hypersensitive response. Plant Journal 44: 258-270.

La Camera S, Geoffroy P, Samaha H, Ndiaye A, Rahim G, Legrand M, Heitz T 2005. A pathogeninducible patatin-like lipid acyl hydrolase facilitates fungal and bacterial host colonization in Arabidopsis. Plant Journal 44: 810-825.

Liu J, Elmore, JM, Fuglsang AT, Palmgren MG,
Staskawicz BJ, Coaker G 2009. RIN4 functions with plasma membrane H+-ATPases to regulate stomatal apertures during pathogen attack. PLoS Biology 7. doi: 10.1371/journal. pbio.1000139

Meimoun P, Mordret E, Langlade NB, Balzergue S, Arribat S, Bailly C, El-Maarouf-Bouteau $\mathrm{H}$ 2014. Is gene transcription involved in seed dry after-ripening? PLoS ONE 9. doi: 10.1371/journal.pone.0086442

Michelotti V, Lamontanara A, Buriani G, Cellini A, Donati I, Vanneste JL, Cattivelli L, Spinelli F, Orro LI, Tacconi G 2015. Unraveling the molecular interaction between Pseudomonas syringae pv. actinidiae (Psa) and the kiwifruit plant through RNAseq approach. Acta Horticulturae 1095: 89-94.

Minic Z 2008. Physiological roles of plant glycoside hydrolases. Planta 227: 723-740.

Morant AV, Jorgensen K, Jorgensen C, Paquette SM, Sanchez-Perez R, Moller BL, Bak S 2008. Betaglucosidases as detonators of plant chemical defense. Phytochemistry 69: 1795-1813.

Mosqueira M, Willmann G, Zeiger U, Khurana TS 2012. Expression profiling reveals novel hypoxic biomarkers in peripheral blood of adult mice exposed to chronic hypoxia. PLoS ONE 7: 10. doi: 10.1371/journal.pone.0037497 Naoumkina MA, Zhao Q, Gallego-Giraldo L, Dai X, Zhao PX, Dixon RA 2010. Genome-wide analysis of phenylpropanoid defence pathways. Molecular Plant Pathology 11: 829-846.

Osbourn AE 1996. Preformed antimicrobial compounds and plant defense against fungal attack. Plant Cell 8: 1821-1831.

Petriccione M, Di Cecco I, Arena S, Scaloni A, Scortichini M 2013. Proteomic changes in Actinidia chinensis shoot during systemic infection with a pandemic Pseudomonas syringae pv. actinidiae strain. Journal of Proteomics 78: 461-476.

Petriccione M, Mastrobuoni F, Zampella L, Scortichini M 2015. Reference gene selection for normalization of RT-qPCR gene expression data from Actinidia deliciosa leaves infected with Pseudomonas syringae pv. actinidiae. Scientific Reports 5. doi: 10.1038/srep16961 
Petriccione M, Salzano AM, Di Cecco I, Scaloni A, Scortichini M 2014. Proteomic analysis of the Actinidia deliciosa leaf apoplast during biotrophic colonization by Pseudomonas syringae pv. actinidiae. Journal of Proteomics 101: 43-62.

Qi YP, Tsuda K, Nguyen LV, Wang X, Lin JS, Murphy AS, Glazebrook J, Thordal-Christensen H, Katagiri F 2011. Physical association of Arabidopsis hypersensitive induced reaction proteins (HIRs) with the immune receptor RPS2. Journal of Biological Chemistry 286: 31297-31307.

Reglinski T, Dann E, Deverall B 2014. Implementation of induced resistance for crop protection. In: Walters DR, Newton AC, Lyon GD eds. Induced resistance for plant defense: a sustainable approach to crop protection. WileyBlackwell, Oxford, England. Pp. 249-299.

Reglinski T, Vanneste JL, Wurms K, Gould E, Spinelli F, Rikkerink E 2013. Using fundamental knowledge of induced resistance to develop control strategies for bacterial canker of kiwifruit caused by Pseudomonas syringae pv. actinidiae. Frontiers in Plant Science 4: 24. doi: 10.3389/fpls.2013.00024

Rikkerink EHA, Mccann HC, Rees-George J, Lu A, Gleave AP, Andersen MT, Rainey PB, Templeton MD 2015. Transposition, insertion, deletion and recombination drive variability in the type 3 secretome of Pseudomonas syringae pv. actinidiae, the transition from global effector comparisons to kiwifruit resistance breeding strategies. In: Vanneste JL ed. I International symposium on bacterial canker of kiwifruit. International Society of Horticultural Science, Leuven, Belgium. Pp. 65-74.

Robatzek S, Somssich IE 2002. Targets of AtWRKY6 regulation during plant senescence and pathogen defense. Genes \& Development 16: 1139-1149.

Thatcher LF, Anderson JP, Singh KB 2005. Plant defence responses: what have we learnt from Arabidopsis? Functional Plant Biology 32: 1-19.

Thomma B, Nurnberger T, Joosten M 2011. Of PAMPs and effectors: the blurred PTI-ETI dichotomy. Plant Cell 23: 4-15.
Vanneste JL 2012. Pseudomonas syringae pv. actinidiae (Psa): a threat to the New Zealand and global kiwifruit industry. New Zealand Journal of Crop and Horticultural Science 40: 265-267.

Vanneste JL, Yu J, Cornish DA, Tanner DJ, Windner R, Chapman JR, Taylor RK, Mackay J, Dowlut S 2013. Identification, virulence and distribution of two biovars of Pseudomonas syringae pv. actinidiae in New Zealand. Plant Disease 97: 708-719.

Walters D, Heil M 2007. Costs and trade-offs associated with induced resistance. Physiological and Molecular Plant Pathology 71: 3-17.

Walters DR, Havis ND, Paterson L, Taylor J, Walsh DJ 2011. Cultivar effects on the expression of induced resistance in spring barley. Plant Disease 95: 595-600.

Wang G, Lovato A, Polverari A, Wang M, Liang YH, Ma YC, Cheng ZM 2014. Genome-wide identification and analysis of mitogen activated protein kinase kinase kinase gene family in grapevine (Vitis vinifera). BMC Plant Biology 14. doi: 10.1186/s12870-014-0219-1

Wurms K, Gould E, Ah Chee A, Taylor J, Reglinski $\mathrm{T}$ 2013. Elicitor induction of defence genes and reduction of bacterial canker in kiwifruit. Acta Phytopathologica Sinica 43 (Suppl.): 256-257.

Wurms KV 2005. Susceptibility to Botrytis cinerea, and curing-induced responses of lytic enzymes and phenolics in fruit of two kiwifruit (Actinidia) cultivars. New Zealand Journal of Crop and Horticultural Science 33: 25-34.

Wurms KV, Ah Chee A, Reglinski T, Taylor JT, Wang MY, Friel EN, Chynoweth R (2011a). Postharvest volatile treatments and preharvest elicitor applications reduce ripe rot incidence in 'Hort16A' kiwifruit. Acta Horticulturae 913: 481-487.

Wurms KV, Reglinski T, Taylor JT, Ah Chee A, Cui W (2011b). Up-regulation of putative defence-associated transcripts correlates with elicitor-induced ripe rot reduction in 'Hort16A' kiwifruit. Acta Horticulturae 913: 525-528.

Zagrobelny M, Bak S, Rasmussen AV, Jorgensen B, Naumann CM, Moller BL (2004). Cyanogenic glucosides and plant-insect interactions. Phytochemistry 65: 293-306. 